Cambridge University in particular has treated its medically qualified demonstrators and lecturers in the preclinical subjects in most niggardly fashion, so that some of my first-class students, now medically qualified, are working for $£ 350$ per annum-with several years of active service thrown in. Cambridge will suffer.

Yet, in spite of financial stringency, I rejoice that I turned a deaf ear to the many temptations to enter private or consultant practice or to accept attractive financial offers from the U.S.A.

\section{Old and Recent Students}

My Old Students.-The best men and women, in the sense of wholeness, are in general practice. Some of the best are in consultant practice. Many of the poorer ones have become specialists, by the acquirement of one of the many tawdry diplomas which clutter up medical education.

The N.H.S. must recognize the difference between the consultant and the specialist. The latter is a man who has specialized in some narrow field. On the other hand the consultant is a man of stature who is consulted by his old students, his fellow students, and even by his teachers. He is not selected on academic attainments but arrives on his prowess as a doctor. This innate difference between consultant and specialist must be recognized sooner or later as a fundamental fact. Moreover, it must be met, as regards financial implications, by a frank public statement as distinct from the present backstair method of merit awards.

My Recent Students.-I advise them to combine some historical perspective with a first-hand knowledge of the structure, function, and habits of Man. William Harvey, Stephen Hales, and Thomas Young are of greater import than May, Fuchs, and Pontecorvo. Faraday, Pasteur, Claude Bernard, and E. H. Starling are of more significance than the Third programme. The Bible and Shakespeare are part of our social heritage and our way of life in a sense that the Bloomsbury and Mayfair novelists never will be.

The health of this country will be improved only by efficiency at the periphery, as distinct from centrally at the Ministry. To achieve this good students must be prepared to enter general practice at the periphery and improve the standard of medicine by continuing as students not only of Medicine in the narrow sense but of the Art of Living in the broad sense. Comenius, as far back as 1657 , said that the function of the university was " to bring sap, vitality, and strength to all." Good anatomists, as well as good doctors, can help to achieve this.

Dr. W. G. Harding, senior assistant medical officer of the London County Council Public Health Department, recently visited Paris (see Medical Officer, June 16, p. 239) in order to make a study of some of the public health and welfare services in that City. He arrived at one institution, for homeless families, just as the residents were eating their midday meal. "The ration issue of macaroni was 80 grammes dry weight (about $3 \mathrm{oz}$.) ; and of boneless meat 100 grammes (about $4 \mathrm{oz}$.) or of meat with bones 120 grammes (about $5 \mathrm{oz}$.), for a meal issue. The quality of the meals was excellent. It seemed almost unbelievable to find later on some of the residents preparing extra dishes on petrol cookers in their own rooms (strictly against the rules) in order to 'supplement' the official diet, which in quality and quantity appeared to be of a standard hardly equalled in our better restaurants. This point illustrates the very different standards of feeding in our two countries."

\section{CONSULTING MEDICINE}

BY

\author{
A. H. DOUTHWAITE, M.D., F.R.C.P. \\ Physician to Guy's Hospital
}

The Editor has suggested that in writing about the career of a medical consultant the subject should be approached in the manner of an autobiography. This, then, is my excuse for an egotistical display usually reserved for those who have retired.

It is always of interest to oneself, and possibly to others, to look for the reasons for adopting medicine as an occupation. Parental influence is probably the most potent factor. Paternal and avuncular example conditioned me, as it were, to the idea of medicine. When approaching matriculation age I finally determined to be a doctor because I loathed bowing to authority and wanted to be my own master. Last, and perhaps not least, an appallingly bad school record in respect of work was leavened by some signs of proficiency in science. I remember a lugubrious headmaster telling me that if I did not take Latin in the matriculation I should for ever be barred from achieving that "plum of the profession" the London M.D. A merciful change of attitude of the University authorities rendered this gloomy prognostication inaccurate.

\section{Medicine or Surgery ?}

Why choose medicine as opposed to surgery? I suppose that most students when they reach the wards have a leaning towards surgery as an art more dramatic in its execution and prompter in its curative effect than the exertions of a physician. To some extent the preclinical period of training may influence the choice, but seldom to a striking degree. I think I can trace the effect of such masters as Starling and Cushny at University College in exciting an interest in the functions and reactions of the human body, but it is probably more a matter of trend of mind. There were others who were fascinated by the intricacies of anatomical structure and who early excelled in this subject. They chose surgery as a natural outlet. During four years' internment in Germany in the first world war I found that pharmacology and physiology could be read with profit, but that the study of anatomy without a corpse was a fruitless labour. This fact, and the opportunity of observing at close quarters four thousand fellow beings of all ages and from all strata of society, directed me to the more contemplative life of the physician. At the end of the war, finding all my friends dead and their places filled by women-a new phenomenon-I departed to the then misogynous atmosphere of Guy's.

I found that within a year of starting clinical work it was possible to be sure in which direction the final choice would lie. Even one's physical attributes may be of importance in determining the future. A surgeon stands for many hours in a hot operating theatre. If he is short and stocky he may feel none the worse. A tall thin man or woman will find prolonged immobility in these circumstances unbearable and productive of such exhaustion that as a life's work it would be unthinkable. The absence of manual dexterity will again tend to divert from surgery, but this is less important, because with determination it can usually be overcome. 
The influence of clinical teachers in deciding whether medicine or surgery shall be embraced is all-important. In my experience it was the registrars who finally settled the question. I had the good fortune to work under two men, mature from experience in the first world war, both to become famous, the one in general medicine, the other in neurology. They were superb teachers, obviously with a sense of vocation, meticulous in the execution of their duties, and never impatient with the ignorance of their ward clerks. They taught medicine not as a condensed summary of the textbook, but as an art to be practised on persons suffering physically and mentally, who needed help primarily from a doctor but also from one who had an understanding of human problems. To the sound grounding which they gave was added the impressive and more discursory teaching of the visiting staff. On the one hand, I was taught by a physician whose care for detail in history-taking and examination emphasized time and again the lesson that any mistake due to carelessness was unforgivable; another chief seemed to possess an effortless flair for diagnosis and a robust belief in the efficacy of drugs given in heroic doses. What a remarkable pair of men they were. They formed a complete contrast in their approach, but they had this in common-nothing was too much trouble to help the sick. It followed that the life of a physician was the only possible goal.

\section{Consulting or General Practice ?}

In the days of which I write, apart from higher qualifications and a good reputation with one's seniors, consulting practice was out of the question unless one had some degree of financial security. Postgraduate jobs were not paid until one reached the stage of registrar. Even at that exalted level it was necessary to have two appointments at hospital in order to earn $£ 250$ per annum. This was thoroughly bad and led many men to leave hospital immediately they were qualified, and, indeed, to take the most meagre qualifications. If registrar status were reached one had to supplement income and lose most valuable time in the soul-destroying occupation of attending pensions boards, or of running night panel practices. I embraced both expedients, and in the tradition of the time developed tuberculosis. This seemed to put an end to any thoughts of becoming a consultant. It proved a blessing in disguise. After six months vegetating in the country I entered general practice in Sussex. It was here that the value of higher qualifications as a substitute for hard cash was apparent. I was offered a share in a most delightful partnership and allowed to pay all expenses out of earnings. No greater incentive to hard work could be devised. The greater the takings of this partnership, the quicker the freedom from debt. A rosy estimate suggested a term of ten years.

I have never regretted my four years in general practice. The intimate problems of the patient and his relatives and of the general practitioner himself can be learned only in this way. It was here that I saw how helpful or how disastrously unhelpful a consultant could be, not so much according to his knowledge, but more on account of what he said or did not say. Within a year or two of starting this work I was rung up by one of my old chiefs with the suggestion that I should apply for a staff vacancy which would soon arise at my old hospital. When I told him my financial position he quite rightly told me to forget all about it.

\section{A Cure for Varicose Veins}

Soon after, a stroke of pure luck brought me back to London. In the 1920's the British Medical Journal carried a series of excerpts of foreign literature. Glancing through this one night I saw that a Dr. Génévrier, of France, stated that he could cure varicose veins by injections of quinine. This was a startling claim in those days. However, I had a woman patient whose life was made miserable by huge varicosities and recurrent ulcers. I asked her whether she would experiment with me. She was to be the guinea-pig, I the experimenter. Such is the faith of patients in their general practitioners that she consented. We proceeded to follow Dr. Génévrier. My first grey hairs appeared at this time as I lay restless at night expecting a call of embolic urgency. All went well. Success was complete. It was not long before I was treating the varicosities of Sussex and neighbouring counties. It is amusing to look back on the reception a short article of mine received when I published the results. Eminent surgeons wrote that the treatment must be wrong because it was contrary to surgical principles. One such rang me up and urged me to stop this evil practice. He said that one had no right to put into a vein substances which one would not take by mouth. When I asked him if he was willing to swallow N.A.B. he slammed down the receiver. We are the best of friends to-day, but the incident is never mentioned.

So many inquiries followed this article that I decided to publish a monograph. No publisher would look at such an effort from an obscure general practitioner, so I paid the expenses and hoped for the best. Edition followed edition, and with this a demand from doctors to treat their patients in London. The next step was to devote my weekly half-day off duty from practice to acquiring a limited consulting practice in town. This I was enabled to do by the generosity of an old surgical friend who put his consulting-room at my disposal. Work flowed in beyond my wildest dreams. Of course the fees were paid into the partnership, but my power of paying off was increased.

\section{A Hospital Appointment}

A second vacancy occurred at my old hospital. This time, with a varicose nucleus on which I could live, I applied and was successful.

The risk of giving up a safe job for a hazardous one was still great. In those days an assistant-physician was paid a honorarium of $£ 100$ a year, and a consultingroom cost $£ 200$ to $£ 300$ a year, to say nothing of the cost of a flat. It used to be reckoned that it took five years before a consultant earned enough to pay his expenses. This gap I escaped, because during my years in Sussex my old students had gone out into practice and started to give me medical consulting work soon after my return. I wonder if any physician forgets the excitement of his first long-distance consultation. The anxiety to give the right diagnosis, to please the even more apprehensive general practitioner, and to satisfy the relations was great. It is a gamble for a general practitioner to call in a young and untried consultant. I hope those who have helped us in our early struggles realize how grateful we are.

Within a year I was able to discard varicose veins, which I had come to detest and which the surgeons had 
now embraced. General medicine was my life for the future, and it has been completely satisfying.

So much for the personal narrative. Now some general notes on the life of a consulting physician.

\section{The Period Between the Wars}

I shall be very brief in dealing with the period between the two wars, because, though of historical interest, they can be of no concern to the student of to-day.

Conditions have undergone a radical change. By this I mean that before 1939 a consultant had, in the absence of private means or appointments with insurance companies, to work for years with a burden of worry. Now no acute fears of insolvency arise, because we are all paid quite well for our hospital work. In the former period it was essential to be always available in the hope of receiving work from overworked seniors, or from general practitioners who could not find their favourite consultant at week-ends. A fortnight's holiday a year for the first ten years and not more than six week-ends a year was the maximum it was wise to take if a large practice was to be built up and held. In addition to teaching hospital work the consultant was usually well advised to serve on the staff of one or more small outlying hospitals in order to make himself known. During the autumn and winter months he would accept invitations to lecture to local medical societies anywhere from Glasgow to Jersey. All this was great fun, but it was exhausting and a strain on even the most robust constitution.

\section{Present Conditions}

Since the institution of the National Health Service the consultant can avoid a lot of unproductive hack work ; he is no longer compelled to hasten into print ; he may reach maturity without a scramble. This is to the good.

Apart from the economic aspect the National Health Service has effected little change. Our work is the same, our pride in our hospitals unchanged, and our loyalty to our colleagues seems to be as firm as ever. An enormous increase in committee work, it must be said, is the fly in the ointment. I believe that young men would still be well advised to practise as part-time hospital consultants and spend the rest of their hours developing a private consulting practice. There is still plenty of scope for it and it helps to preserve the allimportant interest in the patient rather than in the disease. As years go on there is a tendency for a wholetime hospital physician to forget the background of the patients in the wards. Their financial and domestic worries are immensely important. They seldom have an opportunity of unburdening themselves to a doctor in a public ward or out-patient department. There is usually a sense of hurry in out-patient work, unavoidable because of overcrowding, but nevertheless militating against the most valuable exercise in diagnosis-namely, the taking of a patient's history. These are just a few of the reasons. for preserving the private life of a consultant.

If you are practical in your outlook you may be more interested to note that a part-time physician can charge considerable expenses against income tax. On this note another consideration is that a whole-time worker is at the mercy of the Government. A financial crisis has only to be declared and the Treasury may demand a cut in salaries of 10 or $20^{\circ}$. This happened before doctors were Civil Servants and were thus immune. Ask your parents if they remember the Geddes axe.

For established consulting physicians the advent of the National Health Service had but little effect on total incomes. Mos sof a physician's income is derived from fees paid for consultations at his house. The large fees for long-distance calls were falling off long before 1939 for the good reason that consultants were no longer almost limited to London but were to be found in most of the larger cities. The National Health Service may have accentuated this process.

We have on the whole escaped lightly when we compare our lot with the overworked and grossly underpaid general practitioners. They tell me that the whole attitude of the patient to his doctor has changed. He regards his doctor as his paid servant. This is a great pity and can bring nothing but unhappiness to all concerned.

\section{Conclusion}

Finally, if you embrace the life of a consulting physician do not forget that you are consulted by a general practitioner for your opinion on his patient. There must be no direct consultant-patient communications apart from those at the consultation. Your secretary must be instructed to book cases only if the general practitioner wishes for the interview. The patient must never see you again unless the general practitioner is first consulted. A few will slip through the net, when servants are in charge of the telephone, no matter how tightly it be woven. They must be reproved and the practitioner written to with an explanation of how the situation arose.

A consultant who is willing to take patients irrespective of the general practitioner is degrading his status and incidentally storing up endless trouble for himself. He may benefit financially, although even this is doubtful, but he will lose the respect of his fellows. If you achieve recognition, affection, and respect of your colleagues after many years of work what greater prize could you desire?

The National Health Service Act, 1946, increased interest in all phases of hospital work, and this, combined with the growing complexity of modern hospital organization and management, increased the demand for information and advice. The King Edward's Hospital Fund decided that the new situation could best be met by the establishment of a Division of Hospital Facilities. This was done in November, 1948. The division comprises a general information bureau and advisory service, an accounting and financial advisory service, and a library of hospital books, journals, and plans, British and foreign. It has a practically world-wide arrangement with hospital and allied organizations for a regular exchange of information, as a result of which a considerable amount of hospital literature, plans, etc., of other countries, not generally available in Britain, is currently collected. The library contains over 800 books on all aspects of hospital organization and management, and a large number of plans of all types of hospitals. The division visits hospitals, discusses problems, and gives advice. It carries out investigations and surveys and submits reports. At present it is engaged, jointly with the Nuffield Provincial Hospitals Trust, in carrying out a special costing investigation for the Ministry of Health. Another side of the activities of the division is that of receiving hospital visitors from overseas and arranging tours of hospitals for them. This activity is really a two-way service, as hospital officers going abroad with personal introductions from the division are assured of a warm welcome and every possible help. In all cases copies of the reports of these visitors are sent to the division. 